\author{
Jaime J. Jayapalan ${ }^{1}$ \\ Keng L. $\mathrm{Ng}^{2}$ \\ Azad H. A. Razack ${ }^{2}$ \\ Onn H. Hashim ${ }^{1,3}$ \\ ${ }^{1}$ Faculty of Medicine, University \\ of Malaya Centre for Proteomics \\ Research, University of Malaya, \\ Kuala Lumpur, Malaysia \\ ${ }^{2}$ Department of Surgery, Faculty \\ of Medicine, University of \\ Malaya, Kuala Lumpur, \\ Malaysia \\ ${ }^{3}$ Department of Molecular \\ Medicine, Faculty of Medicine, \\ University of Malaya, Kuala \\ Lumpur, Malaysia
}

Received November 10, 2011 Revised February 14, 2012

Accepted February 15, 2012
Research Article

\section{Identification of potential complementary serum biomarkers to differentiate prostate cancer from benign prostatic hyperplasia using gel- and lectin-based proteomics analyses}

\begin{abstract}
Diagnosis of prostate cancer $(\mathrm{PCa})$ is currently much reliant on the invasive and timeconsuming transrectal ultrasound-guided biopsy of the prostate gland, particularly in light of the inefficient use of prostate-specific antigen as its biomarker. In the present study, we have profiled the sera of patients with PCa and benign prostatic hyperplasia (BPH) using the gel- and lectin-based proteomics methods and demonstrated the significant differential expression of apolipoprotein AII, complement C3 beta chain fragment, inter-alpha-trypsin inhibitor heavy chain 4 fragment, transthyretin, alpha-1-antitrypsin, and high molecular weight kininogen (light chain) between the two groups of patients' samples. Our data are suggestive of the potential use of the serum proteins as complementary biomarkers to effectively discriminate $\mathrm{PCa}$ from $\mathrm{BPH}$, although this requires further extensive validation on clinically representative populations.
\end{abstract}

\section{Keywords:}

Benign prostatic hyperplasia / Biomarker / Lectin / Prostate cancer / Proteomics DOI 10.1002/elps.201100608

\section{Introduction}

Early benign prostatic hyperplasia (BPH) is an agingassociated condition of enlarged prostate and voiding dysfunction often due to irregularities in cell proliferation and detrusor muscle underactivity, respectively [1]. A similar clinical presentation is also observed among patients with prostate cancer (PCa) but involving cellular proliferation and differentiation into the malignant stroma tissues and cells, instead [2].

An alarming escalating rate of incidences of $\mathrm{PCa}$ has been observed both in Malaysia [3] and worldwide [4]. This is partly due to increasing use of serum prostate-specific antigen (PSA) as a "screening tool" among men who were concerned with PCa. Thus, the incidence of early-stage PCa is on the

Correspondence: Professor Onn H. Hashim, Department of Molecular Medicine, Faculty of Medicine, University of Malaya, 50603 Kuala Lumpur, Malaysia

E-mail: onnhashim@um.edu.my

Fax: +603-7967-4957

Abbreviations: AAT, alpha-1-antitrypsin; APOA2, apolipoprotein All; BPH, benign prostatic hyperplasia; C3f, complement C3 $\beta$ chain fragment; CGB, champedak galactose binding (lectin); ITIH4f, inter-alpha-trypsin inhibitor heavy chain 4 fragment; KNG, high molecular weight kininogen (light chain); PCa, prostate cancer; PSA, prostate specific antigen; TRUS, transrectal ultrasound; TTR, transthyretin rise as the cancer is detected at an earlier stage rather than the late metastatic stage. PCa is generally attributed to the compounding effects of factors including aging [5], genetic $[6,7]$, ethnicity [8], hereditary [9], and dietary intake [10]. It is also well documented that the incidence of PCa increases with age; rising to about $80 \%$ among men in their $80 \mathrm{~s}[11,12]$.

The comprehensive approach to patients presenting with lower urinary tract symptoms attributed to the prostate gland involves digital rectal examination, uroflowmetry, postvoid residual urine, urinalysis, assessment of validated International Prostate Symptom Score questionnaire, and the measurement of serum PSA. In patients with a suspicious digital rectal examination of hard nodular prostate gland or a raised PSA, a transrectal ultrasound (TRUS) guided biopsy of the prostate gland is required so as to rule out any malignancy on histopathology. Currently, PSA is the most widely used biomarker for PCa but it lacks specificity and sensitivity. Many benign pathologies such as BPH, inflammation, and infection can often cause raised PSA $[1,13,14]$, while on the other hand, patients whose tissue sections demonstrated belligerent PCa features had been shown to have normal PSA levels [15]. If specific biomarkers are made available, TRUS biopsy can be done selectively, thus reducing significantly the number of patients subjected to this procedure.

In light of the increasing incidences of $\mathrm{PCa}$ and the failure of PSA to clearly distinguish $\mathrm{BPH}$ from $\mathrm{PCa}$, novel biomarkers that may be used to predict $\mathrm{PCa}$ at an early stage with high specificity and efficiency are deemed necessary. 
These markers not only assist in the early and accurate identification of PCa patients thus paving the way for new curative treatment modalities but also alleviate needless anguish of those with BPH. It was therefore the aim of the present study to screen for potential serum biomarkers that can discriminate PCa from BPH using proteomics analyses. Aside from the conventional gel-based approach, we have also selectively targeted at proteins that were $O$-glycosylated using a lectin that binds to the $O$-glycans. Many $O$-glycoproteins had previously been implicated with cancer [16-20]. It is therefore interesting to determine if their levels were different between patients with $\mathrm{PCa}$ and $\mathrm{BPH}$.

\section{Materials and methods}

\subsection{Patients' serum samples}

Collection of serum samples was done with patients' consent at the Prostate-TRUS Biopsy clinic, University of Malaya Medical Center, Kuala Lumpur in accordance to a protocol that was approved by the Medical Ethics Committee of the center. Approximately $3 \mathrm{~mL}$ of blood was collected into plain BD vacutainers (Becton, Dickinson \& Co, Franklin Lakes, New Jersey, USA) from subjects with BPH and newly diagnosed patients with stage I or II PCa. Designation of the PCa stages were based on the American Joint Committee on Cancer (AJCC) stage groupings that take both the TNM and histopathological grading into consideration. The specimens were left to stand at room temperature (RT) for $30 \mathrm{~min}$ prior to centrifugation. Serum samples were then carefully collected and kept at $-20^{\circ} \mathrm{C}$ for further use.

\subsection{Assay of PSA}

Quantitative measurements of PSA in patients' serum samples were performed according to the manufacturer's instructions using the ADVIA Centaur System. Table 1 demonstrates the demographics and mean PSA values of subjects involved in the study.

Table 1. Demographic and clinical characteristics of subjects

\begin{tabular}{lll}
\hline Parameters & $\mathrm{BPH}(n=8)$ & PCa $(n=8)$ \\
\hline Ethnicity $\left(\mathrm{M}: \mathrm{C:}^{\mathrm{a})}\right)$ & $1: 5: 2$ & $2: 5: 1$ \\
Age $^{\mathrm{a}}\left(\mathrm{years}{ }^{\mathrm{b})}\right)$ & $65.3 \pm 5.4$ & $69.0 \pm 3.6$ \\
$\mathrm{PSA}^{\mathrm{c})}\left(\mathrm{ng} / \mathrm{mL}^{\mathrm{b})}\right)$ & $6.69 \pm 1.73$ & $29.60 \pm 48.47$ \\
\hline
\end{tabular}

a) M:C:I refers to Malay:Chinese:Indian.

b) Values expressed in mean \pm SD.

c) PSA values of $4 \mathrm{ng} / \mathrm{mL}$ or less are considered normal.

\section{$2.32 \mathrm{DE}$}

2DE was performed using $800 \mu \mathrm{g}$ protein for profiling of neat serum samples $(n=8)$ or $60 \mu$ g pooled O-glycoprotein fractions of the same group of patients that were isolated from champedak galactose binding (CGB) lectin affinity chromatography in a method that was previously described [21]. Samples were initially incubated in $2 \% \mathrm{v} / \mathrm{v}$ IPG sample buffer $\mathrm{pH} 4-7$, containing $9 \mathrm{M}$ urea, $60 \mathrm{mM}$ DTT, and 0.5\% v/v Triton X-100 at room temperature for $30 \mathrm{~min}$. They were then incubated in a rehydration solution containing $8 \mathrm{M}$ urea, $0.5 \%$ v/v IPG buffer, $0.5 \% \mathrm{v} / \mathrm{v}$ Triton X-100 for another $30 \mathrm{~min}$. IPG Immobiline Drystrips pH 4-7, $11 \mathrm{~cm}$ (GE Healthcare, Uppsala, Sweden) were rehydrated in the solution containing the samples and rehydrated overnight. The strips were subjected to isoelectric focusing using the Multiphor Flatbed electrophoresis system (GE Healthcare) for a total duration of $15 \mathrm{kV} / \mathrm{h}$ (Phase 1: $300 \mathrm{~V}, 2 \mathrm{~mA}, 5 \mathrm{~W}, 30 \mathrm{~min}$; Phase 2: $3500 \mathrm{~V}, 2 \mathrm{~mA}, 5 \mathrm{~W}, \sim 4-4.5 \mathrm{~h})$. Focused strips were equilibrated in $1.5 \mathrm{M}$ Tris- $\mathrm{HCl}(\mathrm{pH} 8.8)$ solution containing 6 $\mathrm{M}$ urea, 2\% w/v SDS, 30\% v/v glycerol, and $0.06 \mathrm{M}$ DTT for 15 min on a UNIMAX 2010 platform shaker (Heidolph, Schwabach, Germany), and further incubated in a similar equilibration solution but containing $4.5 \% \mathrm{v} / \mathrm{v}$ iodoacetamide instead of DTT for another $15 \mathrm{~min}$. The equilibrated strips were overlaid onto $8-18 \%$ gradient polyacrylamide gels and electrophoresis was performed following an optimized protocol (Phase 1: $50 \mathrm{~V}, 40 \mathrm{~mA}, 25 \mathrm{~W}$ for $30 \mathrm{~min}$; Phase 2: 600V, $40 \mathrm{~mA}, 25 \mathrm{~W}$ for 1-2 h) using the SE 600 Ruby Electrophoresis System and Power Supply-EPS601 (GE Healthcare).

\subsection{Silver staining of 2DE gels}

Silver staining of the gels 2DE was performed according to the method described by Heukeshoven and Dernick [22]. The electrophoresed gels were initially fixed in a solution containing $40 \% \mathrm{v} / \mathrm{v}$ ethanol and $10 \%$ acetic acid for $30 \mathrm{~min}$. This was followed by incubation in $30 \% \mathrm{v} / \mathrm{v}$ ethanol solution containing $0.5 \mathrm{M}$ sodium acetate, $8 \mathrm{mM}$ sodium thiosulfate, and $0.13 \% \mathrm{v} / \mathrm{v}$ glutaraldehyde for another $30 \mathrm{~min}$. Gels were left to stain in $5.9 \mathrm{mM}$ silver nitrite solution containing $0.02 \% \mathrm{v} / \mathrm{v}$ formaldehyde for $40 \mathrm{~min}$. The resolved proteins were visualized by developing the gels with $0.24 \mathrm{M}$ sodium carbonate solution containing $0.2 \% \mathrm{v} / \mathrm{v}$ formaldehyde. The reaction was finally stopped using a $40 \mathrm{mM}$ EDTA- $\mathrm{Na}_{2} \cdot 2 \mathrm{H}_{2} 0$ solution. For each pooled serum sample, at least three 2DE gel separations were performed. Gels were similarly subjected to the silverstaining method for MS but in the absence of glutaraldehyde [23].

\subsection{Image analysis}

Silver stained 2DE gels and lectin-probed NC blots were scanned using Imaging Densitometer GS690 (Bio-Rad Laboratories, Hercules, California, USA). Expression of proteins 
was analyzed in terms of the percentage of volume contribution using the Image Master 2D Platinum software, version 7.0 (GE Healthcare Biosciences, Uppsala, Sweden). Cut-off parameters were: Smooth -2 ; Saliency -1 ; Min area -5 .

\subsection{Western blotting and CGB lectin detection}

The 2DE-separated proteins were transferred electrophoretically onto NC membranes $(0.45 \mathrm{mM}$; Whatman, Dassel, Germany) using the NovaBlot Kit of the Multiphor ${ }^{\mathrm{TM}}$ II Flatbed System (GE Healthcare Biosciences) for $2 \mathrm{~h}$ at a constant current of $0.8 \mathrm{~mA} / \mathrm{cm}^{2}$ gel. Detection of transferred $O$-glycosylated serum proteins was performed using the CGB lectin that was affinity purified and characterized for its specificity to $O$-glycans using methods that were previously reported [24]. The lectin was then conjugated to horseradish peroxidase before being used to probe for O-glycopeptides on the NC membranes. The membranes were finally developed by means of a colorimetric reaction using diamino-benzoic acid (Bio-Rad Laboratories) as substrates.

\subsection{CGB lectin affinity column chromatography}

The affinity-purified CGB lectin was conjugated to CNBractivated Sepharose 4B according to the manufacturer's instructions (Sigma Chemical, St. Louis, MO, USA). Column was equilibrated with PBS pH 7.2, subsequent to application of approximately $200 \mu \mathrm{L}$ serum samples that were pooled from patients with PCa $(n=8)$ and $\mathrm{BPH}(n=8)$. Fractions were collected and monitored for their absorbance at $280 \mathrm{~nm}$. Elution of bound $O$-glycoprotein-enriched fractions was performed using $0.1 \mathrm{M}$ melibiose in PBS. The bound fractions were pooled and dialyzed against distilled water at $4^{\circ} \mathrm{C}$. The dialysate was then lyophilized and kept at $-20^{\circ} \mathrm{C}$ for subsequent analysis by $2 \mathrm{DE}$.

\subsection{Trypsin digestion and MS}

Identification of protein spots of interest was performed as previously reported [25]. Spots were carefully excised from 2DE gels and destained with $15 \mathrm{mM}$ potassium ferricyanide in $50 \mathrm{mM}$ sodium thiosulphate for $15 \mathrm{~min}$ at RT. The proteins were reduced using $10 \mathrm{mM}$ DTT in $100 \mathrm{mM}$ ammonium bicarbonate solution for $30 \mathrm{~min}$, and alkylated using $55 \mathrm{mM}$ iodoacetamide in the same solution for $20 \mathrm{~min}$, at $60^{\circ} \mathrm{C}$ and in the dark. This was followed by sequential washings with 50 and $100 \%$ ACN, both in $100 \mathrm{mM}$ ammonium bicarbonate solution, and dehydration of the protein spots using vacuum centrifugation. The spots were digested with $6 \mathrm{ng} / \mu \mathrm{L}$ trypsin in $50 \mathrm{mM}$ ammonium bicarbonate at $37^{\circ} \mathrm{C}$, overnight. Peptides were extracted from the gels using 50 and $100 \%$ ACN. Extracted peptides were lyophilized, reconstituted in $0.1 \%$ formic acid, and desalted using the ZipTip columns containing $\mathrm{C}^{18}$ reversed phase media (Millipore, MA, USA).
The sample peptide was mixed with $5 \mathrm{mg} / \mathrm{mL} \alpha$-cyano-4hydroxycinnamic acid at a ratio of $1: 1$, and $0.7 \mu \mathrm{L}$ of the mixture was immediately spotted onto an OptiTOF 384-well insert and analyzed using the 4800 Plus MALDI TOF/TOF analyzer (Applied Biosystem/MDS Sciex, Toronto, Canada).

\subsection{Identification of proteins}

Identification of proteins was performed using the MASCOT search engine [26]. The MS data obtained was searched against Homo sapien entries in the Swiss-Prot database (Last update: 23 October 2008, containing 261513
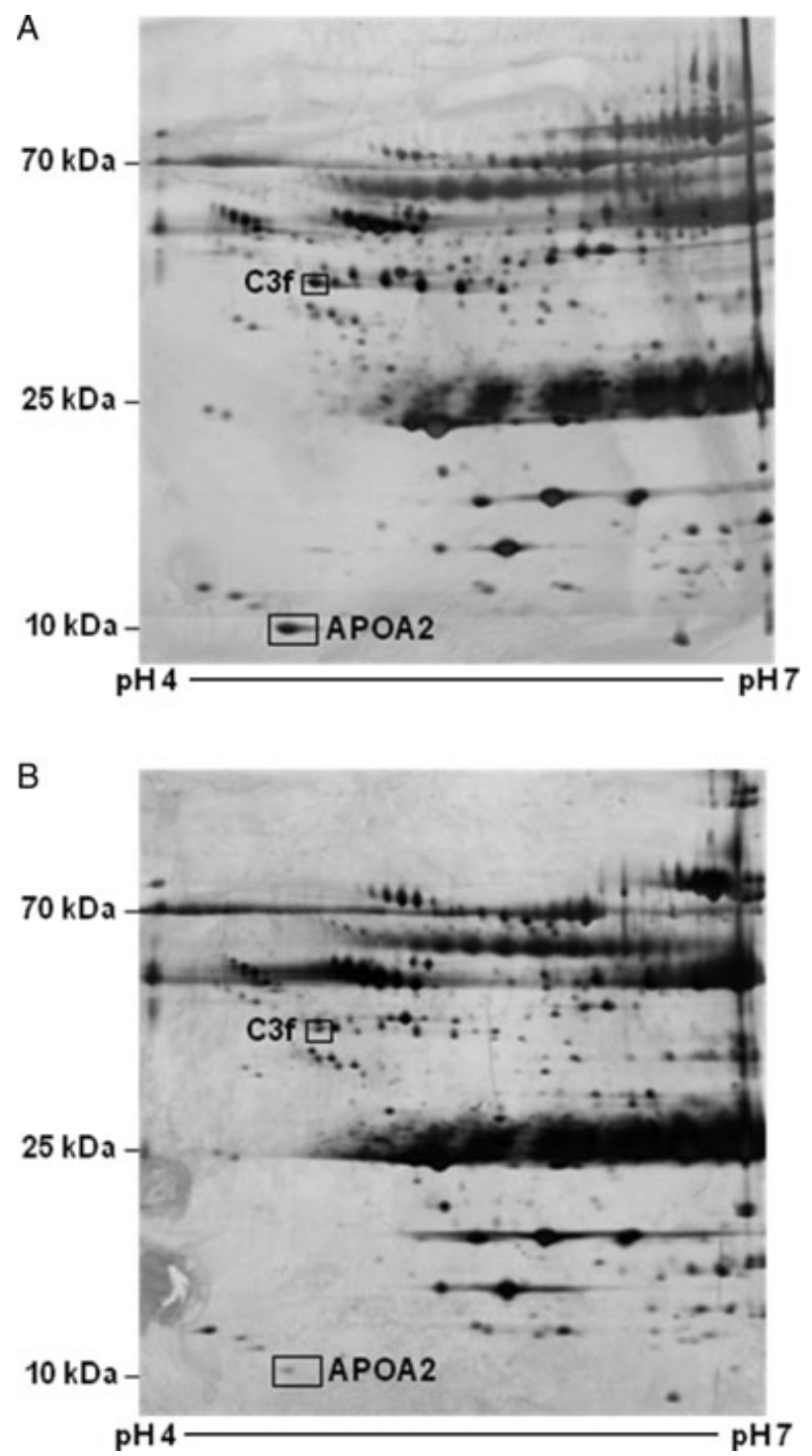

Figure 1. Typical silver stained 2DE protein profiles of sera from patients with $\mathrm{BPH}$ and PCa. (A) Patients with BPH. (B) Patients with $\mathrm{PC}$. Proteins that were differentially expressed are marked on the gels and their identities were confirmed by MS and database search (please refer to Table 2). 
Table 2. Identification of serum proteins that were differentially expressed by MS/MS

\begin{tabular}{|c|c|c|c|c|c|c|c|}
\hline $\begin{array}{l}\text { Spot/ } \\
\text { cluster } \\
\text { ID }\end{array}$ & $\begin{array}{l}\text { Matched } \\
\text { protein } \\
\text { identity }\end{array}$ & $\begin{array}{l}\text { Accession } \\
\text { number } \\
\text { Swiss-Prot) }\end{array}$ & $\begin{array}{l}\text { Theoretical } \\
\text { mass } \\
\text { (Da) }\end{array}$ & $\begin{array}{l}\text { Theoretical } \\
\mathrm{p} /\end{array}$ & $\begin{array}{l}\text { Mascot } \\
\text { score }\end{array}$ & $\begin{array}{l}\text { No. of } \\
\text { peptides } \\
\text { matched }\end{array}$ & $\begin{array}{l}\text { Sequence } \\
\text { coverage } \\
(\%)\end{array}$ \\
\hline APOA2 & Apolipoprotein A-II & P02652 & 11168 & 6.26 & 51 & 1 & 11 \\
\hline $\mathrm{C} 3 \mathrm{f}^{\text {a) }}$ & Complement C3 & P01024 & 187030 & 6.02 & 512 & 7 & 12 \\
\hline $\mathrm{ITIH} 4 \mathrm{f}^{\text {a) }}$ & Inter-alpha-trypsin inhibitor heavy chain $\mathrm{H} 4$ & 014624 & 103261 & 6.51 & 240 & 6 & 6 \\
\hline AAT & Alpha-1 antitrypsin & P01009 & 46707 & 5.37 & 772 & 14 & 38 \\
\hline KNG & High-molecular weight kininogen & P01042 & 71912 & 6.34 & 307 & 7 & 13 \\
\hline TTR & Transthyretin & P02766 & 15877 & 5.52 & 511 & 6 & 49 \\
\hline
\end{tabular}

a) Identified as a protein fragment as indicated by its position in the 2DE gels compared to the parent protein.

sequences) according to the following selection parameters: enzyme - trypsin, missed cleavage -1 , variable modification - 2; (i) carbamidomethylation of cysteine, and (ii) oxidation of methionine, MS precursor ion mass tolerance $-100 \mathrm{ppm}$, MS/MS fragment ion mass tolerance $-0.2 \mathrm{Da}$, and inclusion of monoisotopic masses only.

\subsection{Statistical analysis}

All values are expressed in mean \pm SEM, unless otherwise stated. The Statistical Package for Social Sciences (SPSS) version 17.0 (IBM Corporation, Armonk, New York, USA) was used to analyze the data of our study. The Student's $t$-test was subsequently used to compare means of percentage of volume contribution of the spots between the study groups for all datasets that showed normal distribution. A $p$ value of less than 0.01 was considered significant.

\section{Results}

Figure 1 demonstrates typical representative 2DE profiles generated from neat sera of patients with BPH (panel A) and PCa (panel B), respectively. The technique was able to resolve more than 30 clusters of serum proteins that are relatively of high abundance. However, comparative image analysis of spot volumes of the serum proteins was generally not successful in identifying those that may be specifically used to differentiate BPH from PCa. Only two detected serum proteins, whose identities were confirmed by subjecting their excised 2DE gel spots to analysis by MS/MS and database search (Table 2), were found to be differentially expressed. Apolipoprotein AII (APOA2) and complement C3 $\beta$ chain fragment $(\mathrm{C} 3 \mathrm{f})$, which are common proteins associated with lipoprotein metabolism and general inflammation, respectively, appeared to be downregulated in patients with $\mathrm{PCa}$ compared to those with BPH (Fig. 2A and B). Aside from the database search, $\mathrm{C} 3 \mathrm{f}$ was identified on the basis of its experimental $M_{\mathrm{r}}$ and MS/MS-derived sequences.

In an alternative approach, profiling of the serum was selectively targeted at proteins that were O-glycosylated. Many $O$-glycoproteins had previously been implicated with cancer [16-20], and it is therefore interesting to determine if their levels were different between patients with PCa and those with BPH. Figure 3 demonstrates the 2DE profiles of serum $O$-glycoproteins of patients with $\mathrm{PCa}$ and $\mathrm{BPH}$ that was generated using enzyme-conjugated CGB lectin as probe. The lectin was chosen on the basis of its specific binding to $O$ glycans [24]. With exception of a $35-\mathrm{kDa}$ fragment of ITIH4 (ITIH4f), the expression of all other O-glycopeptides was not significantly altered between patients with BPH compared to those with PCa. The expression of ITIH4f was apparently lower in patients with PCa compared to those with BPH (Fig. 2C), but not significantly different when the western blot data were compared to that similarly obtained from a control group consisting of age-matched normal healthy male subjects (data not shown).

In a separate attempt, we have also resorted to the use of immobilized CGB lectin to selectively isolate $O$-glycoproteins from pooled serum samples. Figure 4 demonstrates typical elution profiles from the affinity separation of pooled serum samples of patients with BPH (panel A) and pooled serum samples from patients with $\mathrm{PCa}$ (panel $\mathrm{B}$ ). The ratio of bound:total protein fractions was apparently similar for both the pooled samples, which was approximately 0.09 . A total of 12 clusters of O-glycopeptides were apparently detected when the enriched melibiose-eluted fractions from $\mathrm{BPH}$ and PCa patients were separately dialyzed and subjected to $2 \mathrm{DE}$ and silver staining (Fig. 5). Three peptide clusters were found to be significantly enhanced in the sera of patients with PCa compared to those with BPH when the 2DE gels were scanned and analyzed by densitometry (Fig. 2D-F). These clusters of peptides were later identified as transthyretin (TTR), high-molecular weight kininogen (KNG), and alpha1-trypsin (AAT) (Table 2). We have also performed a study to test for the possible nonspecific interaction between serum proteins and chromatography media and found that there was none.

\section{Discussion}

With exceptions of APOA2 and complement C3f, none of the other high-abundance serum proteins were found to be differentially expressed when 2DE protein profiles generated from the sera of patients with $\mathrm{BPH}$ were compared with those generated from PCa patients' sera. APOA2 is involved in the 
A

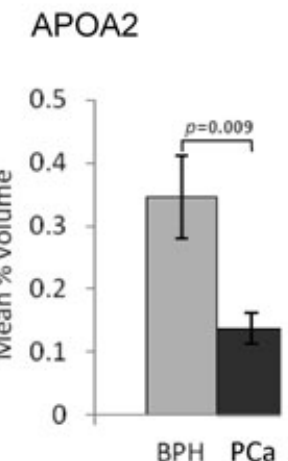

C

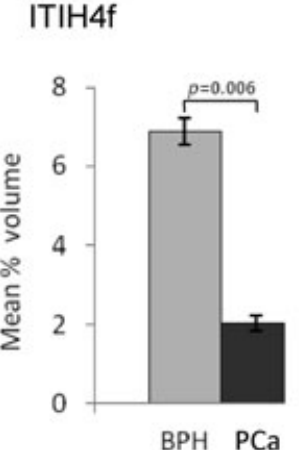

E

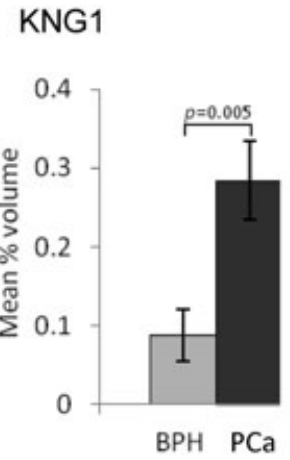

B $\mathrm{C} 3 \mathrm{f}$

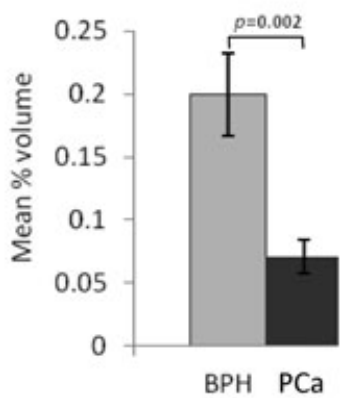

D AAT

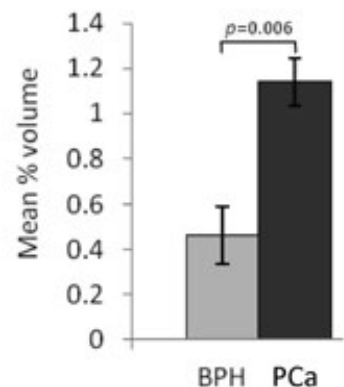

F TTR

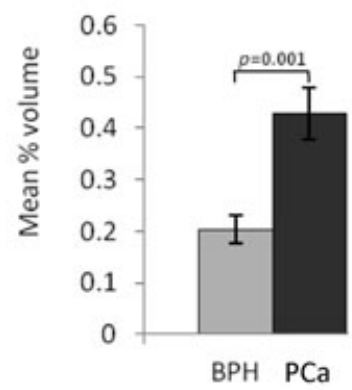

Figure 2. Volume contribution of proteins that were differentially expressed between patients with BPH and PCa. Percentage of volume contribution of protein spots was analyzed using ImageMaster ${ }^{\mathrm{TM}}$ 2D Platinum software, version 7.0. (A and $B$ ) Clusters of protein spots that were detected by silver staining of 2DE gels (Fig. 1); (C) Analysis of $O$-glycopeptides detected by enzyme-conjugated CGB lectin (Fig. 3). (D-F) Serum proteins that were detected subsequent to CGB lectin affinity chromatography (Fig. 5). The standard deviation (SD) shown in (A) and (B) are from biological replicates while those in $(\mathrm{C}-\mathrm{F})$ are from technical replicates.

metabolism of high-density lipoprotein and its deficiency may result in hypercholesterolemia [27]; while native C3 plays a general role in the activation of both the classical and alternative pathways of complement and patients with deficiency of C3 are generally susceptible to bacterial infection [28]. Due to their nonspecific functions and association with diverse pathological conditions, APOA2 and C3f may not be suit-

A

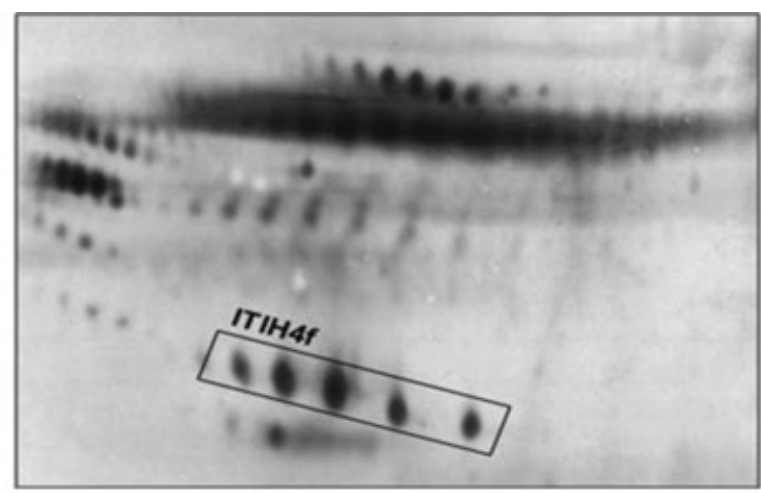

B

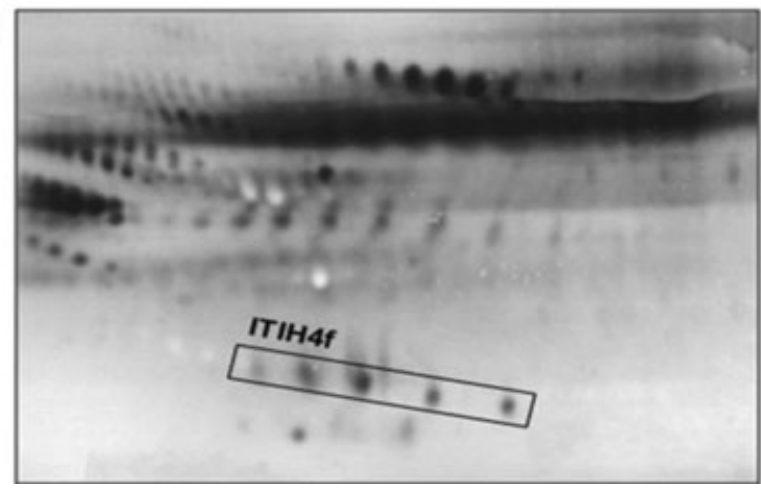

Figure 3. Detection of $O$-glycosylated serum proteins using enzyme-conjugated CGB lectin. Enzyme-conjugated CGB lectin was used to probe for $O$-glycosylated proteins from sera that were subjected to $2 \mathrm{DE}$ and transferred onto NC membranes. Identity of the sole protein that was differentially expressed was confirmed by MS (please refer to Table 2). (A) Patients with BPH. (B) Patients with PCa. The differentially expressed protein spots are marked in boxes. Acidic sides of the NC membranes are to the left and $M_{\mathrm{r}}$ declines from the top.

able for use as independent biomarkers. Nonetheless, it is interesting to note that the $9-\mathrm{kDa} \mathrm{C} 3$ cleaved fragment, C3a, has been reported to be elevated in patients with hepatocellular carcinoma [29], breast cancer [30], and colorectal cancer $[31,32]$. This is compatible with the diminished amounts of C3 seen in the PCa patients in this study.

When enzyme-conjugated CGB lectin was used to detect 2DE separated O-glycosylated proteins on NC membrane, only ITIH4f was found to be differentially expressed. Contrary to our earlier expectation, expression of the $35-\mathrm{kDa} O$ glycopeptide fragment was significantly lower in patients with PCa compared to those with BPH and its levels were not significantly different compared to those obtained from normal healthy control subjects. We have previously reported the significant enhanced levels of ITIH4f selectively in patients with cancers that are associated with increased levels of estrogens $[24,26]$. The sex steroid hormones may have induced kallikrein to cleave native $120-\mathrm{kDa}$ ITIH4 into its 85 - and 35 $\mathrm{kDa}$ fragments [33] in these cancers, the latter fragment of 

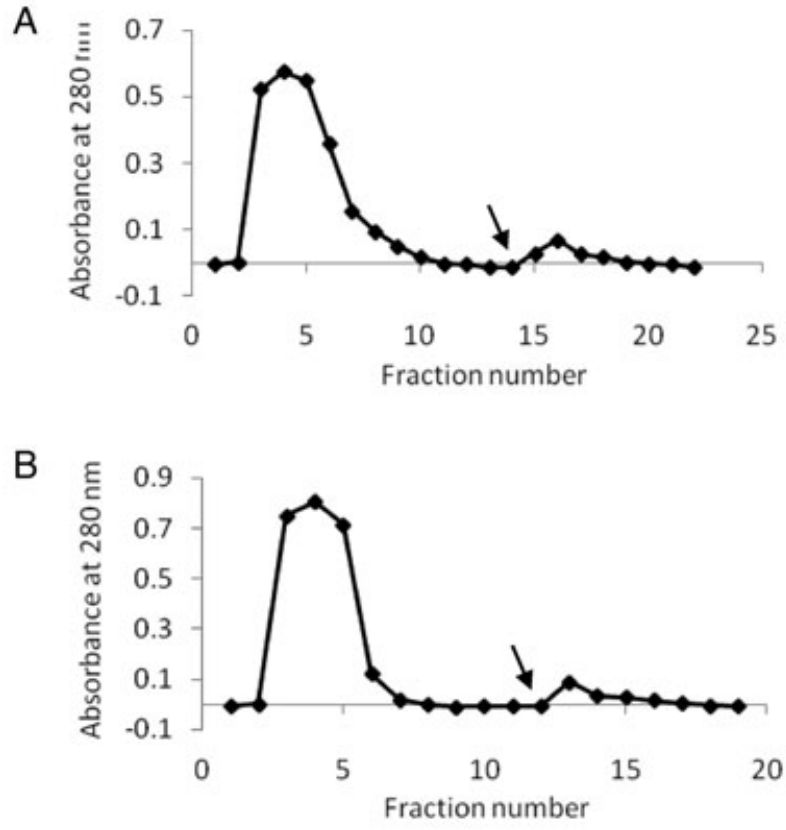

Figure 4. Isolation of $O$-glycosylated serum proteins using CGB lectin affinity chromatography. Pooled serum samples from patients with $\mathrm{BPH}(\mathrm{A})$ and $\mathrm{PCa}(\mathrm{B})$ were separately subjected to $\mathrm{CGB}$ lectin affinity chromatography. Collected fractions were monitored by measurement of absorbance at $280 \mathrm{~nm}$. Arrows indicate start of elution using $0.1 \mathrm{M}$ melibiose in PBS.

which is $O$-glycosylated and thus detected by the CGB lectin. However, the data of the present study appear not to be in line with our previous findings, as PCa is now known to be associated with increased levels of serum estradiol [34]. The different altered levels of ITIH $4 \mathrm{f}$ expression in PCa and BPH patients further suggest the contributing effect of androgens since the hormones are also upregulated in patients with $\mathrm{PCa}$ and that both estrogens and androgens are believed to be the causing factors for prostate malignancy [35].

The use of immobilized CGB lectin in the affinity isolation of $O$-glycosylated serum proteins from patients further demonstrated the significant enhanced expression of KNG, AAT, and TTR in serum samples of patients with PCa compared to those with BPH. The KNG spots that were resolved in the 2DE gels were the $O$-glycosylated light chain component of cleaved high molecular weight kininogen. Our present data appear to indicate that BPH and PCa are opposite of breast, endometrial, and cervical cancers in their levels of serum KNG since we had previously shown that KNG was depleted in the women cancer patients [24]. This apparent contradiction is again most likely attributed to the differences in the ratio of the sex steroid hormones of men and women cancer patients.

In cases of AAT and TTR, the mechanism by which they were retained by the immobilized CGB lectin is not clear as the proteins are not known to be $O$-glycosylated [36] and their spot clusters were also not detected in the earlier western
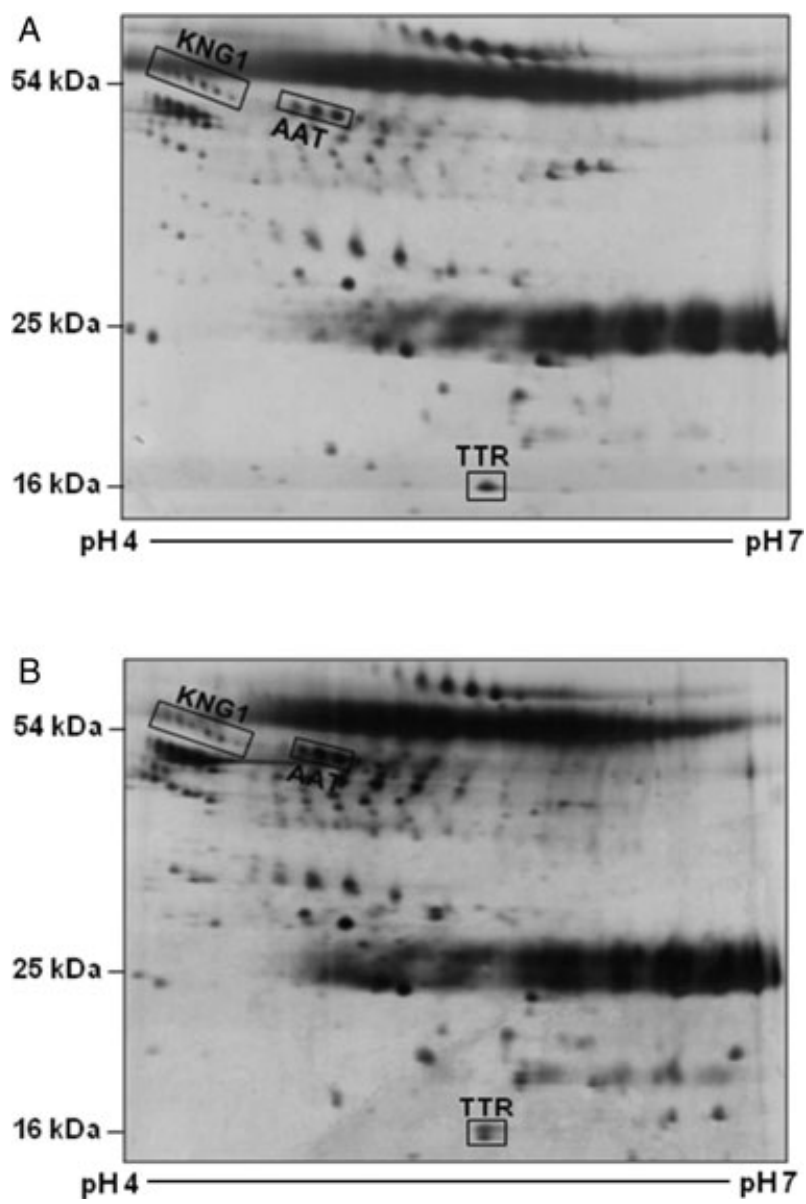

Figure 5. Glycoproteomic profiling of $O$-glycosylated serum proteins isolated by CGB lectin affinity chromatography. Pooled neat serum samples were subjected to CGB lectin affinity chromatography. Analysis of the CGB-bound fractions was performed by 2-DE and silver staining. (A) Patients with BPH. (B) Patients with $\mathrm{PCa}$. Identities of proteins that were differentially expressed were confirmed by MS and database search (please refer to Table 2).

blot experiments that used enzyme-conjugated CGB lectin as probe. Hence, their retention was most likely due to indirect interactions with other $O$-glycosylated serum proteins, which are yet to be confirmed. While this is ambiguous for AAT, it is not totally unexpected for TTR as the protein is rather promiscuous in its interaction and is known to bind to many aromatic compounds [37,38]. TTR has been earlier identified as a potential biomarker for ovarian [39], colorectal [31], and lung [40] cancers. It may have been retained by the CGB lectin affinity column in this study via its interaction with retinol-retinol binding protein 4 (RBP4) complex, although it is currently not known if RBP4 is indeed O-glycosylated. Alternatively, TTR could have interacted with the sex hormone binding globulin (SHBG), which is known to possess the O-linked oligosaccharides [41].

When taken together, the data of this study are suggestive of the potential use of APOA2, C3f, ITIH4f, KNG, AAT, and TTR as complementary biomarkers to effectively discrimi- 
nate PCa from $\mathrm{BPH}$. It is hoped that the new biomarkers would be able to assist clinicians in identifying patients who are at a higher risk for PCa. However, this requires further extensive validation in a study that has to be carefully designed, particularly when the identified serum proteins have been individually implicated in many other pathological conditions. Such a study must also be carried out on clinically representative populations and therefore not possibly performed using the present gel- and lectin-based proteomics approaches. With the identification of the potential biomarkers in the present study, validation is easily carried out in a large-scale investigation using assays such as the simple or multiplex ELISA.

This work was funded by the HIR-MOHE H-20001-00E000009 and RG127-10AFR research grants from the University of Malaya, Kuala Lumpur.

The authors have declared no conflict of interest.

\section{References}

[1] Thorpe, A., Neal, D., Lancet 2003, 361, 1359-1367.

[2] Guess, H. A., Epidemiol. Rev. 2001, 23, 152-158.

[3] Rampal, S., Lim, G. C. C., Halimah, Y., Cancer Incidence in Peninsular Malaysia 2003-2005, Ministry of Health, Kuala Lumpur, Malaysia, Kuala Lumpur 2008.

[4] Jemal, A., Bray, F., Center, M. M., Ferlay, J., Ward, E., Forman, D., CA A Cancer J. Clin. 2011, 61, 69-90.

[5] Hankey, B. F., Feuer, E. J., Clegg, L. X., Hayes, R. B., Legler, J. M., Prorok, P. C., Ries, L. A., Merrill, R. M., Kaplan, R. S., J. Natl. Cancer Inst. 1999, 91, 1017-1024.

[6] Mitra, A., Fisher, C., Foster, C. S., Jameson, C., Barbachanno, Y., Bartlett, J., Bancroft, E., Doherty, R., KoteJarai, J., Peock, S., Easton, D., IMPACT, and EMBRACE, Collaborators, Eeles, R., Br. J. Cancer 2008, 98, 502-507.

[7] Liede, A., Karlan, B. Y., Narod, S. A., J. Clin. Oncol. 2004, 22, 735-742.

[8] Ben-Shlomo, Y., Evans, S., Ibrahim, F., Patel, B., Anson, K., Chinegwundoh, F., Corbishley, C., Dorling, D., Thomas, B., Gillatt, D., Kirby, R., Muir, G., Nargund, V., Popert, R., Metcalfe, C., Persad, R., Eur. Urol. 2008, 53, 99-105.

[9] Bratt, O., J. Urol. 2002, 168, 906-913.

[10] Chan, J. M., Giovannucci, E. L., Epidemiol. Rev. 2001, 23, 87-92.

[11] Sakr, W. A., Grignon, D. J., Haas, G. P., Heilbrun, L. K., Pontes, J. E., Crissman, J. D., Eur. Urol. 1996, 30, 138144.

[12] Ries, L. A. G., Melbert, D., Krapcho, M., Stinchcomb, D. G., Howlader, N., Horner, M. J., Mariotto, A., Miller, B. A., Feuer, E. J., Altekruse, S. F., Lewis, D. R., Clegg, L., Eisner, M. P., Reichman, M., Edwards, B. K., SEER Cancer Statistics Review 1975-2005, National Cancer Institute, Bethesda, MD 2008.

[13] Gümüş, B. H., Neşe, N., Gündüz, M. I., Kandiloğlu, A. R., Ceylan, Y., Büyüksu, C., Int. Urol. Nephrol. 2004, 36, 549-553.
[14] Hochreiter, W. W., Andrologia 2008, 40, 130-133.

[15] Törnblom, M., Norming, U., Adolfsson, J., Becker, C., Abrahamsson, P.-A., Lilja, H., Gustafsson, O., Urology 1999, 53, 945-950.

[16] Brockhausen, I., EMBO Rep. 2006, 7, 599-604.

[17] Batra, S. K., Mukhopadhyay, P., Chakraborty, S., Ponnusamy, M. P., Lakshmanan, I., Jain, M., Biochim. Biophys. Acta. 2011, 1815, 224-240.

[18] Abdul-Rahman, P. S., Lim, B. K., Hashim, O. H., Electrophoresis 2007, 28, 1989-1996.

[19] Chen, Y., Lim, B. K., Peh, S. C., Abdul-Rahman, P. S., Hashim, O. H., Proteome Sci. 2008, 6, 20.

[20] Mohamed, E., Abdul-Rahman, P. S., Doustjalali, S. R., Chen, Y., Lim, B. K., Omar, S. O., Bustam, A. Z., Singh, V. A., Mohd-Taib, N. A., Yip, C. H., Hashim, O. H., Electrophoresis 2008, 29, 2645-2650.

[21] Doustjalali, S. R., Yusof, R., Yip, C. H., Looi, L. M., Pillay, B., Hashim, O. H., Electrophoresis 2004, 25, 2392-2401.

[22] Heukeshoven, J., Dernick, R., Electrophoresis 1988, 9, 28-32.

[23] Yan, J. X., Wait, R., Berkelman, T., Harry, R. A., Westbrook, J. A., Wheeler, C. H., Dunn, M. J., Electrophoresis 2000, 21, 3666-3672.

[24] Rahman, M., Anuar Karsani, S., Othman, I., Shafinaz Abdul Rahman, P., Haji Hashim, O., Biochem. Biophys. Res. Commun. 2002, 295, 1007-1013.

[25] Seriramalu, R., Pang, W. W., Jayapalan, J. J., Mohamed, E., Abdul-Rahman, P. S., Bustam, A. Z., Khoo, A. S.-B., Hashim, O. H., Electrophoresis 2010, 31, 23882395.

[26] Perkins, D. N., Pappin, D. J. C., Creasy, D. M., Cottrell, J. S., Electrophoresis 1999, 20, 3551-3567.

[27] Kalopissis, A.-D., Pastier, D., Chambaz, J., Current Opin. Lipidol. 2003, 14, 165-172.

[28] Walport, M. J., in: Warrell, D. A., Cox, T. M., Firth, J. D. (Eds.), Oxford Textbook of Medicine, Oxford University Press Inc., New York 2003, pp. 160-166.

[29] Kanmura, S., Uto, H., Sato, Y., Kumagai, K., Sasaki, F., Moriuchi, A., Oketani, M., Ido, A., Nagata, K., Hayashi, K., Stuver, S., Tsubouchi, H., J. Gastroenterol. 2010, 45, 459-467.

[30] Fan, Y., Wang, J., Yang, Y., Liu, Q., Fan, Y., Yu, J., Zheng, S., Li, M., Wang, J., J. Cancer Res. Clin. Oncol. 2010, 136, 1243-1254.

[31] Fentz, A. K., Sporl, M., Spangenberg, J., List, H. J., Zornig, C., Dorner, A., Layer, P., Juhl, H., David, K. A., Proteomics Clin. Appl. 2007, 1, 536-544.

[32] Ward, D. G., Suggett, N., Cheng, Y., Wei, W., Johnson, H., Billingham, L. J., Ismail, T., Wakelam, M. J. O., Johnson, P. J., Martin, A., Br. J. Cancer 2006, 94, 1898-1905.

[33] Saguchi, K., Tobe, T., Hashimoto, K., Sano, Y., Nakano, Y., Miura, N. H., Tomita, M., J. Biochem. 1995, 117, 14-18.

[34] Carruba, G., J. Cell. Biochem. 2007, 102, 899-911.

[35] Risbridger, G. P., Bianco, J. J., Ellem, S. J., McPherson, S. J., Endocr. Relat. Cancer 2003, 10, 187-191.

[36] Liu, T., Qian, W. J., Gritsenko, M. A., Camp, D. G., 2nd, Monroe, M. E., Moore, R. J., Smith, R. D., J. Proteome Res. 2005, 4, 2070-2080. 
[37] Bekki, K., Takigami, H., Suzuki, G., Tang, N., Hayakawa, K., J. Health Sci. 2009, 55, 601-610.

[38] Weiss, J. M., Andersson, P. L., Lamoree, M. H., Leonards, P. E., van Leeuwen, S. P., Hamers, T., Toxicol. Sci. 2009, 109, 206-216.

[39] Zhang, Z., Bast, R. C., Yu, Y., Li, J., Sokoll, L. J., Rai, A. J., Rosenzweig, J. M., Cameron, B., Wang, Y. Y., Meng, X.-Y., Berchuck, A., van Haaften-Day, C., Hacker, N. F., de
Bruijn, H. W. A., van der Zee, A. G. J., Jacobs, I. J., Fung, E. T., Chan, D. W., Cancer Res. 2004, 64, 5882-5890.

[40] Liu, L., Sun, S., Liu, J., Wu, S., Dai, S., Wang, X., Huang, L., Xiao, X., He, D., Chin. J. Lung Cancer 2009, 12, 300305.

[41] Raineri, M., Catalano, M. G., Hammond, G. L., Avvakumov, G. V., Frairia, R., Fortunati, N., Mol. Cell. Endocrinol. 2002, 189, 135-143. 